\title{
Analysis on the International Situation and Evolution of Research: Quantitative Analysis on the SSCI Theses from 2005 to $2014^{*}$
}

\author{
Jingqian Tang \\ Library of Jinan University, Guangzhou, China \\ Email: tjqswx@jnu.edu.cn
}

Received 7 December 2015; accepted 24 December 2015; published 30 December 2015

Copyright (C) 2015 by author and Scientific Research Publishing Inc.

This work is licensed under the Creative Commons Attribution International License (CC BY). http://creativecommons.org/licenses/by/4.0/

(c) (i) Open Access

\begin{abstract}
Bibliometrics and descriptive statistical analysis on the research papers published on the 74 kinds of journals of journalism and communication included in SSCI from 2005 to 2014 will be conducted through key variables, like annual distribution, regional distribution, research institutional distribution, authors distribution, frontier of research, knowledge base and its evolution, subject impact index, etc. From the qualitative and quantitative perspective, we will reveal the international posture of journalism research and the international prestige and potential problems in studies of journalism and communication in Mainland China to promote the internationalization process of domestic journalism and communication research.
\end{abstract}

Keywords

Journalism and Communication, SSCI, Document Statistics and Analysis, Internationalization

\section{Introduction}

Journalism and communication is one of the most popular research directions in the humanities and social sciences and the internationalization of the research results is a major problem. In recent years, concerning China's journalism and communication studies, the vision, and the scope of it has expanded, but the depth is insufficient and the academic level is not high enough. Some scholars believe that strengthening method training and grasping the international theory research is the key to improving the academic level of China's journalism and communication studies (Liao et al., 2014). Therefore, it is urgent to establish the international awareness of the

\footnotetext{
"This paper is one of the results of Jinan University Degree and Graduate Education Teaching and Research project "Scientific research auxiliary tools for graduate students" (No. 14MS26).

How to cite this paper: Tang, J. Q. (2015). Analysis on the International Situation and Evolution of Research: Quantitative Analysis on the SSCI Theses from 2005 to 2014. Advances in Journalism and Communication, 3, 100-109. 
research on journalism and communication, to understand and master the research orientation, the research trends and the development trend of the international mainstream academic journals and representative results. However, the wave of big data is coming, mastering and using correctly the empirical research methods to deal with the mass of information is a challenge for the journalism and communication researchers. Science Citation Index Social (SSCI) is generally considered to be an important tool for collecting data from various fields of social science. The number and level of the papers published in the journals included in the SSCI can reflect the degree of internationalization (Liu \& Liu, 2009). Journalism and communication science is an important subject of SSCI, which is helpful to promote the development of domestic journalism and communication, and to promote the international progress of the academic achievements and academic journals. Some scholars had carried on the analysis of the study of journalism and communication in China on the basis of SSCI. For example, Li Wu, Huang Pei and other scholars take the research papers of journalism and communication included in the SSCI, A\&HCI and CPCI-SSH as the study subject, to dissert on the foreign new media research progress from several perspectives by using mapping knowledge domain (Li, Huang, \& Li, 2013; Liu et al. 2013; Li, 2013). The analysis and discussion undoubtedly have given us great help to understand some part of the present international situation of the research on journalism and communication science. However, there are still shortcomings on the aspects such as the holistic overview of journalism and communication studies, especially the study of the frontier, knowledge base and the whole evolution characteristics, and the effect of journalism and communication research on other disciplines, etc. In view of this, this paper takes research papers published on 74 kinds of journal of journalism and communication studies included in SSCI from 2005 to 2014 as research object. We try to answer the following questions: 1 ) what kinds of form features do journalism and communication study papers included in SSCI take on? What are the evolution characteristics of them? 2) What major issues do journalism and communication study papers included in SSCI concern? What is the frontier area, the knowledge base and the evolution of the research? 3) What are the implications of these papers on the research field of social science?

\section{Data Sources and Analysis Methods}

\subsection{Data Sources}

JCR data show that there are 74 kinds of journal of journalism and communication included in the SSCI (38 in Britain, 25 in the United States, 4 in Holland, 3 in Germany, 1 in Spain, 1 in Switzerland, 1 in Australia, 1 in Slovenia). Concerning the research field they are involved, in addition to the research of journalism and communication, these journals are also involved in psychology, business, linguistics, library and information science, political science and other fields (Table 1). Retrieve simultaneously in the two fields of Publication Name and Published Year in SSCI. The preliminary retrieval results include 30,100 records and there are 20,647 of re-

Table 1. Journals of journalism and communication included in SSCI (IF > 1.5).

\begin{tabular}{|c|c|c|c|c|}
\hline Publication source & Publication cycle & Country & IF( 2013) & Other subjects \\
\hline Communication Research & Bimonthly & America & 2.444 & No \\
\hline Research on Language and Social Interaction & Quarterly & Britain & 2.421 & Psychology, Linguistics \\
\hline Journal of Communication & Bimonthly & America & 2.076 & No \\
\hline New Media Society & Monthly & Britain & 2.052 & No \\
\hline Public Opinion Quarterly & Bimonthly & Britain & 2.033 & Political Science、Social Sciences \\
\hline Journal of Computer-Mediated Communication & Quarterly & America & 2.019 & Library and Information Science \\
\hline Public Understanding of Science & Bimonthly & Britain & 1.932 & Philosophy of history \\
\hline Human Communication Research & Quarterly & America & 1.886 & No \\
\hline Journal of Health Communication & Monthly & America & 1.869 & Library and Information Science \\
\hline Political Communication & Quarterly & America & 1.825 & Political Science \\
\hline International Journal of Press-Politics & Quarterly & America & 1.761 & Political Science \\
\hline International Journal of Advertising & Bimonthly & Britain & 1.754 & Business \\
\hline Journal of Advertising Research & Quarterly & America & 1.651 & Business \\
\hline Interaction Studies & 3 Issues/year & Holland & 1.564 & Linguistics \\
\hline
\end{tabular}


search papers, 6878 of book reviews, others are conference abstracts, editorial material, communication and news, etc. After above retrieval, 20,647 of sample papers are obtained excluding editorials, news, biographies, book reviews, conference abstracts and other types of documents.

\subsection{Methods and Tools}

This paper will carry on analysis of the basic characteristics, research frontier, knowledge base, discipline influence and other aspects of the papers in journalism and communication included in SSCI in order to answer the above questions. 1) For the basic characteristics of the papers, we select the annual distribution, national/regional distribution, research institutions, the authors distribution and other variables of sample papers to carry on statistical analysis by using Online Analyzer of SSCI database; 2) For the research frontier of the papers, we select the author key words of sample papers (Author Keyword field in SSCI database) to carry on data processing and statistical analysis by using Endnote, Excel and Citespace. 3) For the knowledge base of the papers, we select the reference literature (References Cited field in SSCI database) of sample papers and use Citespace software to carry on the visual analysis, and use Excel and Endnote to carry out data processing and statistical analysis; 4) For the discipline influence of the papers, we select literature from sample papers(Citing Articles field in SSCI database) to carry on citation analysis to reveal the impact of journalism and communication studies included in SSCI on other social sciences field.

\section{Data Analysis}

\subsection{Basic Features of Journalism and Communication Research Papers}

The total number of journalism research papers published on 74 kinds of journals during 2005-2014 is 20,647 and the annual distribution and change trend is shown in Figure 1. The data shows that the annual output of the research papers in the field of journalism and communication studies is stable and the average output is about 192 every year in the 10 years. These papers are from 115 countries/regions respectively, showing a trend of focus on a small number of countries/regions. The total number of papers of the top 10 countries is 18,317 which accounts for $88.72 \%$ of the total. Among them, a total of 10,903 papers of the United States accounted for 52.81\% of the total (see Table 2), which is the most. It is worth noting that, although the data in Table 2 shows that China (not including Taiwan) ranks ninth place with 586 papers, but there are only 183 published papers, of which the first author or the corresponding author are from mainland China. The number of papers published by the author from Hong Kong is 259 and from Macao District is 20. There are 124 papers for cooperation. This indicates that the international visibility and influence level of the research achievement of journalism and communication in the Mainland China is very low and the research level is not only significantly behind the western developed countries, such as the United States and other western countries, but also there is a big gap behind Hong Kong. One of the important obstacles may be the language problem: English in the SSCI papers accounted for the absolute advantage. In the sample papers there are 20,245 ones are written in English, accounting for $98.05 \%$ of the total. In addition, China has not yet any kind of periodical of journalism and communication studies to be collected by SSCI, which also greatly restricted the pace of the research results of China's journalism and communication studies to the world.

The research status of representative writers group in a certain subject field reflects the trend of the research in this field. We can grasp the depth and breadth of the research field of journalism and communication by analyzing those representative writers group. From the ranking of the number of papers published by the Research Institute (see Table 3), we can see there are 9 American universities published more than 200 papers, which indicates that the United States occupies the leading place in the research field of the international journalism and communication. From the number of papers published by the author (see Table 4), we can see there are 16 people published more than 25 papers, among whom 10 are from the United States, 3 from Holland, 1 each from Hong Kong, Taiwan and Belgium. There is no doubt that these scholars, especially from the United States, are the leading figures in the study of journalism and communication, and have an immeasurable effect on the promotion of its research.

\subsection{Frontier and Knowledge Base of Journalism and Communication Research Papers}

The research area normally can be defined as a series of related issues and concepts, which are concerned by the 


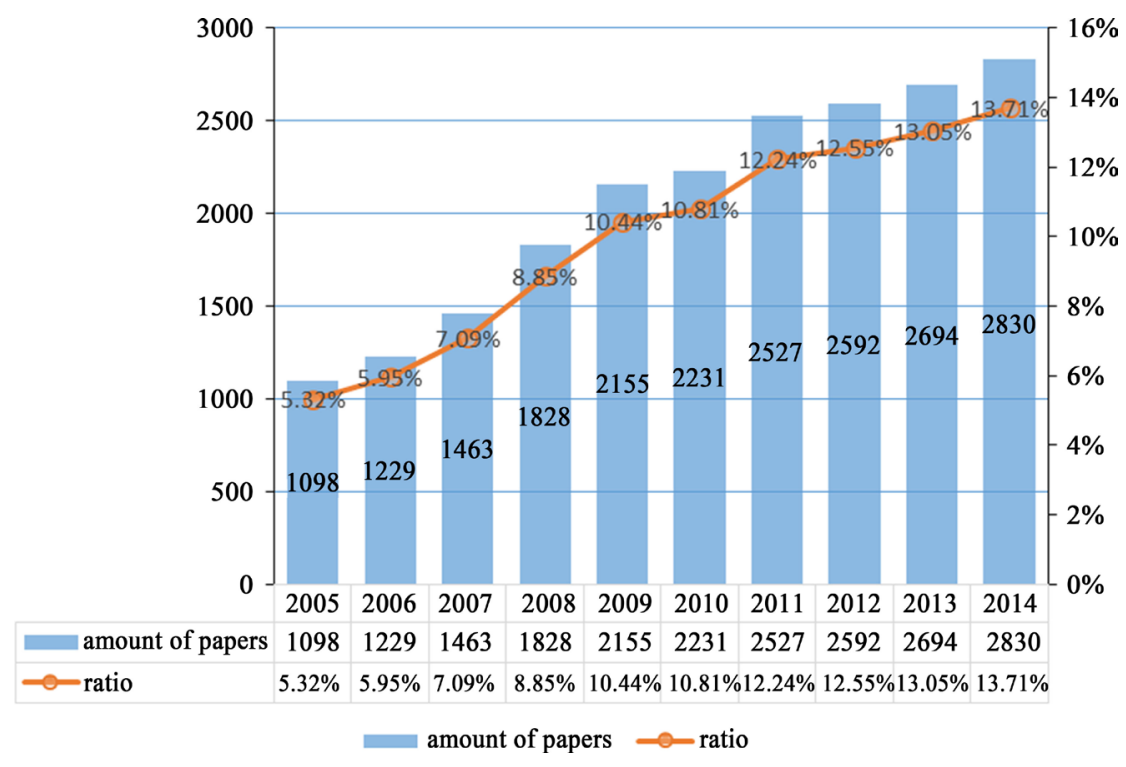

Figure 1. Annual distribution of the journalism and communication papers.

Table 2. Countries/regions distribution of the journalism and communication papers (Top 10).

\begin{tabular}{cccc}
\hline Countries/Regions & Number of papers & Proportion & Cumulative ratio \\
\hline America & 10,903 & $52.81 \%$ & $52.81 \%$ \\
Britain & 1694 & $8.21 \%$ & $61.01 \%$ \\
Australia & 1384 & $6.70 \%$ & $67.72 \%$ \\
Holland & 925 & $4.48 \%$ & $72.20 \%$ \\
Canada & 730 & $3.54 \%$ & $75.73 \%$ \\
Germany & 631 & $3.06 \%$ & $88.79 \%$ \\
Spain & 598 & $2.90 \%$ & $84.58 \%$ \\
China (including Hong Kong, Macao) & 586 & $2.84 \%$ & $86.89 \%$ \\
Korea & 490 & $2.37 \%$ & $88.72 \%$ \\
\hline
\end{tabular}

Table 3. Research Institute distribution of the journalism and communication papers (number of papers > 200).

\begin{tabular}{|c|c|c|c|}
\hline Organization name & Country & Number of papers & Proportion \\
\hline Wisconsin University & America & 400 & $1.94 \%$ \\
\hline University of Illinois & America & 361 & $1.75 \%$ \\
\hline Michigan State University & America & 358 & $1.73 \%$ \\
\hline University of Amsterdam & Holland & 336 & $1.63 \%$ \\
\hline University of Texas at Austin & America & 323 & $1.56 \%$ \\
\hline Ohio State University-Columbus & America & 320 & $1.55 \%$ \\
\hline Pennsylvania State University & America & 312 & $1.51 \%$ \\
\hline University of Pennsylvania & America & 266 & $1.29 \%$ \\
\hline University of Georgia & America & 232 & $1.12 \%$ \\
\hline Indiana University & America & 227 & $1.10 \%$ \\
\hline Purdue University & America & 223 & $1.08 \%$ \\
\hline University of North Carolina & America & 222 & $1.08 \%$ \\
\hline University of Michigan & America & 216 & $1.05 \%$ \\
\hline University of Missouri & America & 210 & $1.02 \%$ \\
\hline University of Calif Santa Barbara & America & 202 & $0.98 \%$ \\
\hline
\end{tabular}


Table 4. Authors distribution of the journalism and communication papers (number of papers $>25$ ).

\begin{tabular}{llc}
\hline \multicolumn{1}{c}{ Author's name } & \multicolumn{1}{c}{ Research institution } & Number of papers \\
\hline Valkenburg, Patti M. & University of Amsterdam (Holland) & 33 \\
Scheufele, Dietram A. & Wisconsin University (America) & 33 \\
Knobloch-Westerwick, Silvia & Ohio State University-Columbus (America) & 33 \\
de Vreese, Claes H. & Leiden University (Holland) & 32 \\
Lee, Francis L. F. & The Chinese University of Hong Kong (China) & 32 \\
Chang ChingChing & National Chengchi University (Taiwan) & 30 \\
d'Haenens, Leen & The University of Leuven (Belgium) & 28 \\
Paek, Hye-Jin & Michigan State University (America) & 28 \\
Walther, Joseph B. & Michigan State University (America) & 27 \\
Niederdeppe, Jeff & Cornell University (America) & 27 \\
Shah, Dhavan V. & Wisconsin University (America) & 26 \\
Peter, Jochen & University of Amsterdam (Holland) & 26 \\
Dutta, Mohan J. & Purdue University (America) & 26 \\
Brossard, Dominique & Wisconsin University (America) & 25 \\
Tamborini, Ron & Michigan State University (America) & 25 \\
Levine, Timothy R. & Michigan State University (America) & \\
\hline
\end{tabular}

academic community. The key words and their frequency distributions are often used to reveal the subject areas of their research (Chen, 2006). If we take a series of related issues and concepts concerned by the highly cited papers lately published in the last several years as the latest developments in the field, then the references of the frontier study form their knowledge base (Persson, 1994). Therefore, through statistics and analysis of the highly cited papers and keywords of the references of these papers published during 2005-2014, we reveal the frontiers, knowledge base and the evolution process of the journalism and communication research

\subsubsection{Analysis of the Frontier Areas of Journalism and Communication Research Papers}

Statistics indicates that during 2005-2014 there are 14,389 SSCI papers quoted more than once in journalism and communication research, which accounted for $69.69 \%$ of the total number of the sample papers. The highest cited times of a single paper was 659. The total number of keywords in these 14,389 papers was 36,038 (the average number of keywords in each paper is 2.5). After classification, summarization and eliminating numbers, symbols and words that means nothing substantive to the journalism and communication study area, the results of using Citespace software to do visualization analysis are shown as Figure 2. In particular, the keywords with frequency more than 600 times are in Table 5. After using Citespace to further analyze the link between high frequency keywords, we found that (Figure 2): communication, media, Internet, information, has been the research hotspots of journalism and communication in recent ten years. In recent years, the main focus of the frontier areas of journalism and communication research is on the following areas: 1) the study mainly on news reports. The study mainly concerns the application of mass-media in the news reports, the media of the news reports, press and the news reports of journalism and communication in the field of natural science, such as climate change, etc.; 2) in social support area, the study mainly concerns stress, adjustment of personality and quality, physical and mental health of family, children, adolescents and women, etc., such as depression, breastcancer, et al.; 3) The study on interpersonal relationship including close relationship and romantic relationship, etc.; 4) through analysis of the sharp changes of key words We can find the new research areas of journalism and communication , such as the application of Twitter, Facebook and other social media and computer media on journalism and communication.

\subsubsection{Analysis of the Knowledge Base of Journalism and Communication Research}

As mentioned above, the references of these 20,647 sample papers constitute the knowledge basis of journalism and communication research. Therefore, we can reveal the knowledge basis of the journalism and communication research though analyzing these references, especially the highly cited ones. We got the following results as 


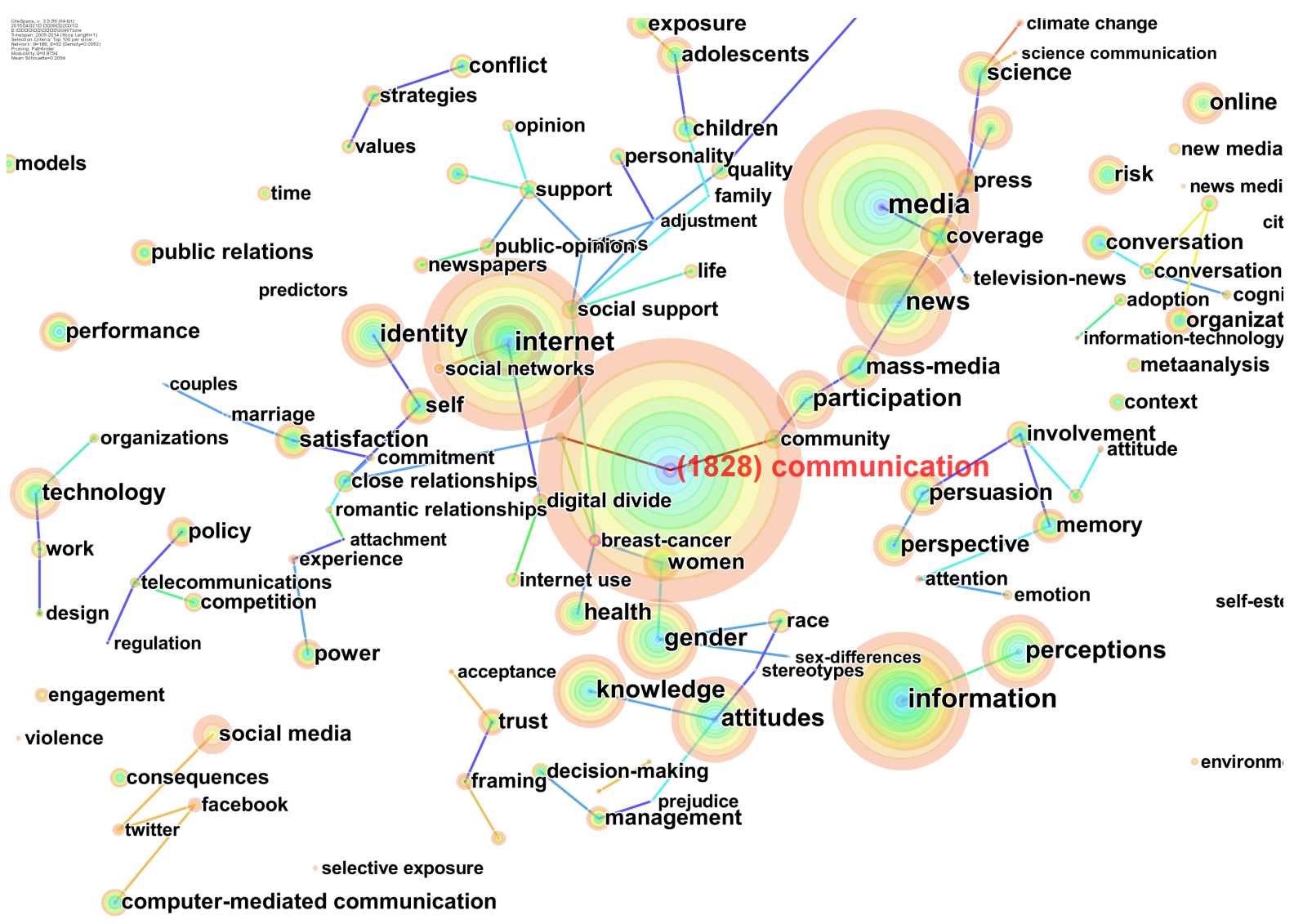

Figure 2. Relation map of high frequency keywords from high cited papers.

Table 5. High frequency keywords from high cited papers (frequency $>600$ ).

\begin{tabular}{cccc}
\hline Keywords & Frequency & Keywords & Frequency \\
\hline Business & 2048 & Television & 822 \\
Linguistic & 1854 & Language \& Linguistic & 820 \\
Information Science \& Library Science & 1842 & Culture Studies & 810 \\
Media & 1595 & Model & 805 \\
Film, Radio, Television & 1418 & Impact & 710 \\
Psychology, Social & 1344 & Gender & 669 \\
Internet & 1256 & Health Policy \& Services & 647 \\
Sociology & 1210 & Discourse & 642 \\
Information & 1084 & Management & 640 \\
Political Science & 998 & Telecommunications & 623 \\
Behavior & 914 & Knowledge & 619 \\
News & 902 & Perceptions & 603 \\
\hline
\end{tabular}

shown in Figure 3 and Figure 4 by using Citespace software to visualize all the references analysis. In particular, the top 20 researchers whose papers are cited most frequently and their representative references are in Table 6. After further analysis we found the following characteristics: 1) Concerning the representative researchers, the research achievement of Scheufele, D.A., Iyengar, S., Eveland, W.P., Bandura, A., Entman, R.M. constitute the core references of the journalism and communication studies included in SSCI (Table 6). 2) Concerning the area and content of the research, these knowledge basis are related to the role of Communication theory and television news in social life, and the contrast of the influence of publication, broadcasting and internet in communication, 


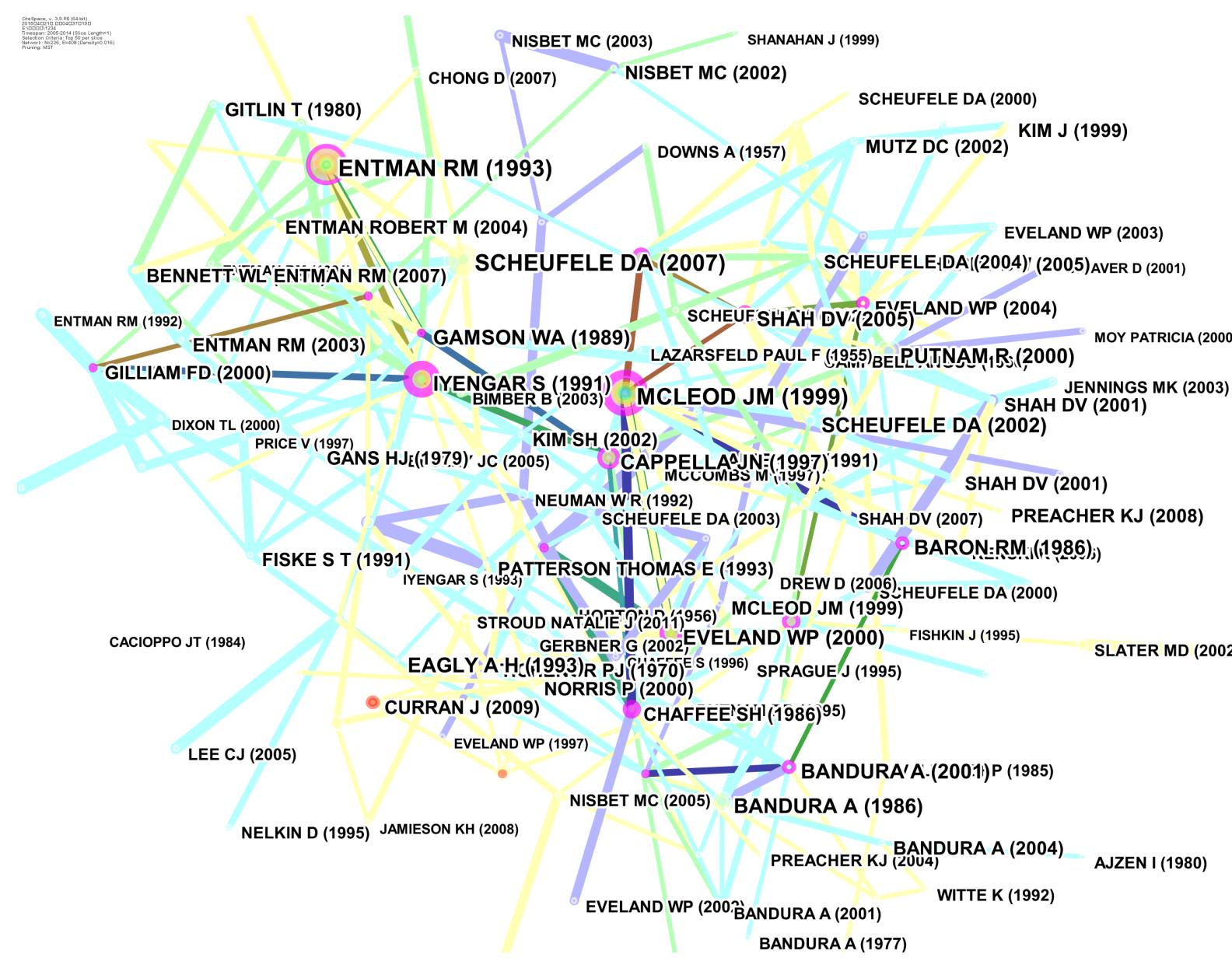

Figure 3. Relation map of high frequency documents of the journalism and communication papers.

context and community. For example, Scheufele, D.A. discusses the evolution of the following three models: framework, agenda setting and prediction (Scheufele \& Tewksbury, 2007). Another example, Iyengar, S. studies the impact of television news on the citizen cognition of international affairs (Iyengar, 1987). 3) Concerning the relationship between the reference and the cited (see Figure 3 and Figure 4), these core reference documents still have a guiding significance on today's journalism and communication study and are the focus of the follow-up study. And there is also an academic inheritance relationship between these core reference documents which shows a clear knowledge accumulation effect.

\section{Influence of Journalism and Communication Papers by Subject Category}

The citation of a paper is often used to evaluate the academic influence of that paper. In this paper, to reveal the influence of journalism and communication research on other subjects, we carry out analysis of subject categories on the citation of the research papers included in SSCI. As mentioned above, the total number of journalism and communication research papers included in SSCI cited more than once is 14,389 during 2005-2014 and the total cited number is 122,672 . Due to the limitation of the number of samples, we carried out analysis on the 5000 papers which were cited the most. These papers were incited 97,022 times and 50,499 references were cited, except for the 48,068 self-citation. The analysis results are shown in Table 7. Firstly, this shows that the degree of cross-level and mutual influence between journalism and communication studies and Psychology is quite high. Secondly, the research results of journalism and communication studies are also cited in business and economics, public environment occupational health, computer science, linguistics, sociology, library and information science, government law, education and teaching, Health Sciences, engineering, environmental ecology and other social sciences, which shows that the influence of journalism and communication studies is very ex- 


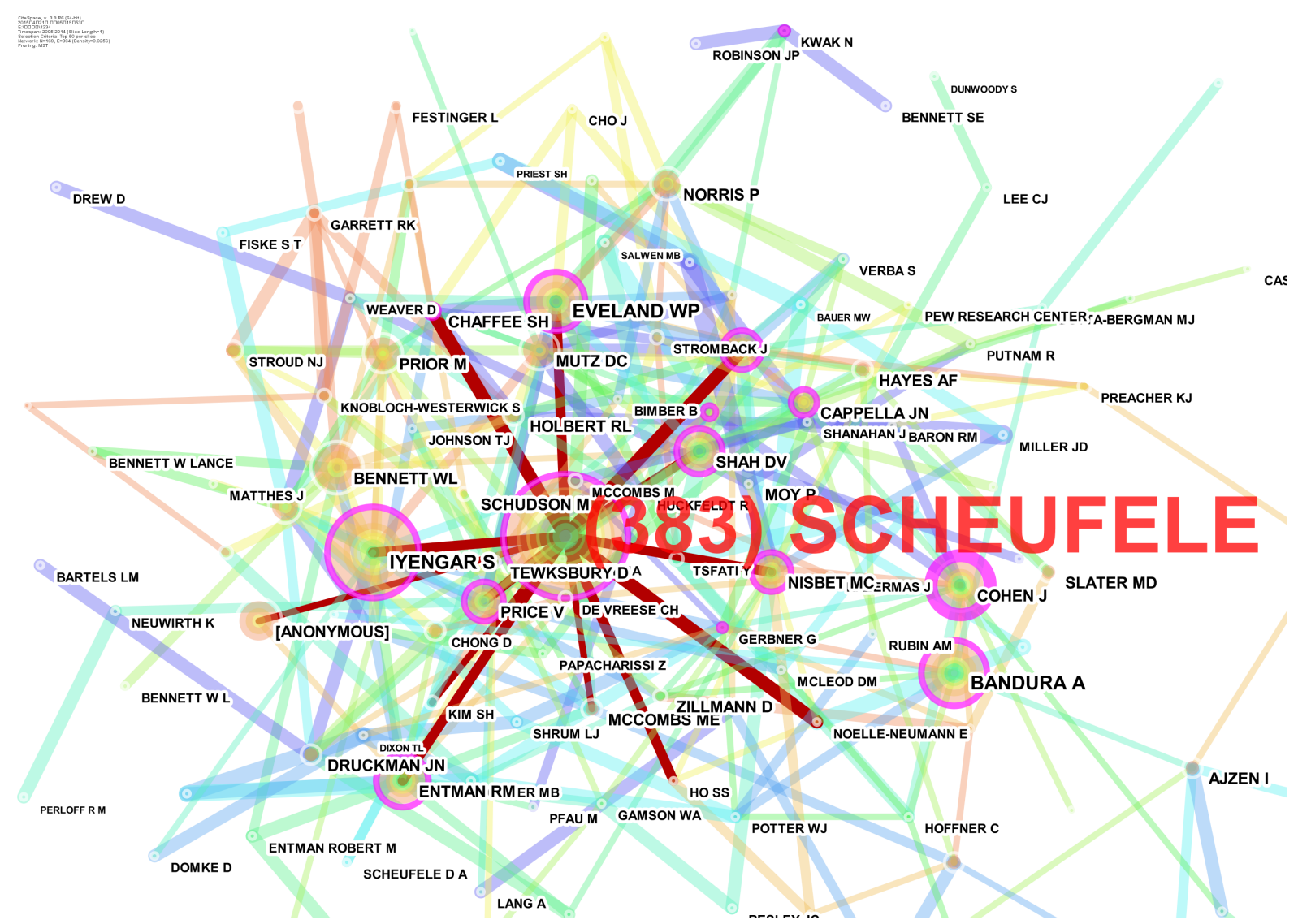

Figure 4. Relation map of high frequency authors of the journalism and communication papers.

Table 6. High frequency authors and their representative literatures of journalism and communication papers (Top 20).

\begin{tabular}{|c|c|c|c|}
\hline Author & $\begin{array}{l}\text { Total cited } \\
\text { frequency }\end{array}$ & Representative literature & $\begin{array}{l}\text { Representatives } \\
\text { cited times }\end{array}$ \\
\hline Scheufele, D.A. & 383 & $\begin{array}{l}\text { Framing, agenda setting, and priming: The evolution of three media effects } \\
\text { models (2007) }\end{array}$ & 268 \\
\hline Ingra, $\mathrm{S}$. & 322 & Television-news and citizens explanations of national affairs (1987) & 95 \\
\hline Eveland, W.P. & 253 & $\begin{array}{l}\text { Interactions and nonlinearity in mass communication: Connecting theory and } \\
\text { methodology (1997) }\end{array}$ & 44 \\
\hline Bandura, A. & 245 & $\begin{array}{l}\text { A comparative test of status envy, social power, and secondary reinforcement } \\
\text { theories of identificatory learning (1963) }\end{array}$ & 109 \\
\hline Entman, R.M. & 213 & Blacks in the news - television, modern racism and cultural-change (1992) & 158 \\
\hline Cohen, J. & 204 & $\begin{array}{l}\text { Abuse and violence history of men and women in treatment for } \\
\text { methamphetamine dependence (2003) }\end{array}$ & 65 \\
\hline Price, V. & 202 & $\begin{array}{l}\text { New values and public opinion: A theoretical account of media priming and } \\
\text { framing (1997) }\end{array}$ & 95 \\
\hline Shah, D.V. & 177 & $\begin{array}{l}\text { Communication, context, and community - An exploration of print, broadcast, } \\
\text { and Internet influences (2001) }\end{array}$ & 177 \\
\hline Mcleod, J.M. & 170 & $\begin{array}{l}\text { Understanding deliberation - The effects of discussion networks on participation } \\
\text { in a public forum (1999) }\end{array}$ & 81 \\
\hline Mutz, D.C. & 165 & The consequences of cross-cutting networks for political participation (2002) & 165 \\
\hline Bennett, W.L. & 162 & Toward a theory of press-state relations in the united-states (1990) & 102 \\
\hline Zaller, J. & 160 & Information, values, and opinion (1991) & 87 \\
\hline Nisbet, M.C. & 146 & $\begin{array}{l}\text { Pathways to political participation? Religion, communication contexts, and mass } \\
\text { media (2003) }\end{array}$ & 44 \\
\hline
\end{tabular}




\begin{tabular}{|c|c|c|c|}
\hline \multicolumn{4}{|l|}{ Continued } \\
\hline Norris, $\mathbf{P}$. & 139 & “To entertain, inform, and educate”: Still the role of public television (2001) & 45 \\
\hline Prior, M. & 138 & $\begin{array}{l}\text { Post-Broadcast Democracy: How Media Choice Increases Inequality in Political } \\
\text { Involvement and Polarizes Elections (2007) }\end{array}$ & 138 \\
\hline Chaffee, S.H. & 122 & Political knowledge and the campaign media of 1992 (1994) & 96 \\
\hline $\begin{array}{l}\text { Cappella, } \\
\text { J.N. }\end{array}$ & 113 & $\begin{array}{l}\text { Argument repertoire as a reliable and valid measure of opinion quality: Electronic } \\
\text { dialogue during campaign } 2000 \text { (2002) }\end{array}$ & 56 \\
\hline Ajzen, I. & 109 & Attitudes, personality and behavior (1988) & 103 \\
\hline Petty, R.E. & 108 & $\begin{array}{l}\text { Mass media attitude change: implications of the elaboration likelihood model of } \\
\text { persuasion (2002) }\end{array}$ & 41 \\
\hline Zillmann, D. & 106 & $\begin{array}{l}\text { Female responses to provocation after exposure to aggressive and erotic films } \\
\text { (1978) }\end{array}$ & 20 \\
\hline
\end{tabular}

Table 7. Distribution of journalism and communication citing articles (Top 20).

\begin{tabular}{lcc}
\hline \multicolumn{1}{c}{ Subject category } & Citation quantity & Proportion \\
\hline Psychology & 8999 & 21.036 \\
Communication & 8769 & 20.498 \\
Business Economics & 5166 & 12.076 \\
Public Environmental Occupational Health & 3024 & 7.069 \\
Computer Science & 2922 & 6.83 \\
Social Sciences Other Topics & 2913 & 6.809 \\
Linguistics & 2388 & 5.582 \\
Sociology & 2306 & 5.39 \\
Information Science Library Science & 2289 & 5.351 \\
Government Law & 2227 & 5.206 \\
Education Educational Research & 2102 & 4.914 \\
Health Care Sciences Services & 1648 & 3.852 \\
Engineering & 1282 & 2.997 \\
Environmental Sciences Ecology & 1202 & 2.81 \\
Psychiatry & 735 & 1.718 \\
Biomedical Social Sciences & 677 & 1.583 \\
Family Studies & 675 & 1.578 \\
General Internal Medicine & 651 & 1.522 \\
Public Administration & 579 & 1.353 \\
Substance Abuse & 552 & 1.29 \\
\hline
\end{tabular}

tensive and the interdisciplinary study of the journalism and communication is becoming more and more powerful.

\section{Discussion}

Through carrying out literature measurement analysis and descriptive statistical analysis on the journalism and communication research papers included in SSCI during 2005-2014 and combing related literatures, we revealed the basic situation of the research on the International journalism and communication in the last ten years: 1) The European and American countries represented by the United States, Britain and Holland occupy the dominant position leading the international journalism and communication study. While the study of journalism and communication in mainland China is lagging far behind the international level; 2) Business, Media, Internet and Information Science and so on are the most concerned areas of journalism and communication studies. Facebook and Twitter and so on are emerging research areas; 3 ) Internationally, the research on the journalism and 
communication shows the characteristic of problem-solving orientated and the micro application based, which pays great attention to the guiding role of the research on the educational practice, and has a relatively clear knowledge accumulation and academic inheritance path; 4) The influence of journalism and communication studies on other subjects is increasing, which shows the interdisciplinary characteristics of social science research from another side.

Through comparative analysis of domestic journalism and communication studies, we find the following phenomena and problems: 1) The international visibility and international level of the domestic journalism and communication studies are relatively low and the number of papers written by the authors from mainland China is only 183 among 14,389 samples. Although it may be related to the factors such as periodical source and language barrier, the key lies in the theory of the research itself is not strong and the depth of the research is not enough. 2) Domestic journalism and communication studies tend to take a more macro perspective and many research papers have been staying at the basic study on the theory of journalism and communication, business knowledge and development model, without reflecting the practical application of journalism and communication. Furthermore, the specific practice of journalism and communication in the business, economic and social livelihood and other areas needs to be strengthened. 3) The achievements of the domestic journalism and communication studies are more simple repetition and show obvious characteristics of knowledge fragmentation. Their theoretical foundation is weak and their effect on the knowledge accumulation and development of the journalism and communication is not obvious. 4) In the 20,647 journalism and communication research papers, only 234 papers were co-authored by Chinese authors and foreign authors, which showed deficiency in international cooperation and exchange. In order to change this situation, the researchers of journalism and communication need to establish the international awareness, to track and learn from the advanced research results and methods, to optimize the main content, structure and discipline distribution, to strengthen international cooperation and academic exchanges, and to strive to improve the international status of domestic journalism and communication studies and academic visibility on the basis of focusing on the specific situation in China.

\section{References}

Chen, C. M. (2006). Citespace II: Detecting and Visualizing Emerging Trends and Transient Patterns in Scientific Literature. Journal of the American Society for Information Science \& Technology, 57, 359-377. http://dx.doi.org/10.1002/asi.20317

Iyengar, S. (1987). Television News and Citizens’ Explanations of National Affairs. American Political Science Review, 81, 815-831. http://dx.doi.org/10.2307/1962678

Li, W. (2013). The Publication Trends of the International Journal of Journalism and Communication: Measurement Analysis on the SSCI Articles. Publishing Research, 1, 85-89.

Li, W., Huang, P., \& Li, X. J. (2013). International Research Advance of New Media Based on Mapping Knowledge Domain. Journal of Beijing University of Posts and Telecommunications (Social Sciences Edition), No. 2, 18-24.

Liao, S. Q., Shen, Q., Liu, C. Y. et al. (2014). Journalism and Communication Studies of China Mainland from 1998-2012. Journalism Bimonthly, 6, 70-82.

Liu, L., \& Liu, N. C. (2009). Bibliometric Analysis of SSCI Publications of China from 1978-2007. Information Science, 10, 1590-1594.

Liu, Z. X., Liu, N. H., Ma, K. et al. (2013). Review of Journalism and Communication Research in China of the Year: Analysis Based on 9 Kinds of CSSCI Journals. Modern Communication (Journal of Communication University of China), 3 , 41-48.

Persson, O. (1994). The Intellectual Base and Research Fronts of JASIS 1986-1990. Journal of the American Society for Information Science, 45, 31-38. http://dx.doi.org/10.1002/(SICI)1097-4571(199401)45:1<31::AID-ASI4>3.0

Scheufele, D. A., \& Tewksbury, D. (2007). Framing, Agenda Setting, and Priming: The Evolution of Three Media Effects Models. Journal of Communication, 57, 9-20. 